\title{
In and about the poetic line
}

\author{
DONNA A. VAN DE WATER and DANIEL C. O'CONNELL \\ Loyola University, Chicago, Illinois
}

\begin{abstract}
The present paper defends the relatively greater importance of punctuation over lineation for the prediction of pauses, and consequently for the temporal unitization of oral readings of poetry. Nine poems of Seamus Heaney, read by the author himself, are analyzed. In terms of two response measures, percentage of available positions used for pauses and mean duration of these pauses, the greater importance of punctuated relative to line-end positions is dramatically confirmed. More than $90 \%$ of the overall pause time is accounted for by punctuation. In each of the poems, both response measures are accounted for by punctuation rather than line-end position.
\end{abstract}

Recent research has indicated a renewed interest in the poetic line as a performance unit in oral reading. Dillon (1976) summarized the matter by stating that "readers aim for at least one pause per line, usually line final, but also line medial"' (p. 12). Lehiste's (1984) position was stated modestly: "The poetic line constitutes a unit of temporal programming in at least some languages, including English and Estonian"' (p. 9). A stronger position was expressed by Turner and Pöppel (1983): "The LINE is preceded and followed by a distinct pause (not neccessarily a pause for breath), which, despite the presence of other pauses within the line divides the verse into clearly identifiable pieces"' (p. 286). They concluded by emphatically asserting "the extra-ordinary prevalence of the 3-second LINE in human poetry" (p. 293).

Hartman (1980) has also recently proposed that lineation plays a very important role: "Verse is language in lines" (p. 11). More closely:

There is a dichotomy-not a spectrum - between verse and prose. Lineation distinguishes them. . . . [V]erse is harder to read than prose. One reason is that unless one willfully ignores lineation, one pauses at the end of each line. ${ }^{2}$ Whatever else this pause may do, it forces the reader to slow down and pay more attention to what he is reading. (p. 52)

In his footnote (2), Hartman acknowledged that the statement about line-end pauses is remarkably hard to prove, and that he was in any event less interested in acoustical than in psychological facts.

At first reading, Hartman's thesis seems quite clear, but the matter is not that simple. He reverts to the feelings of "a reader"; however, it is not clear what reader. He excludes, on the basis of the "performative fallacy," the use of any particular performance or sets of performances to identify a poem (p. 38; also Wimsatt \& Beards-

The authors' mailing address is: Psychology Department, Damen Hall 619, Loyola University of Chicago, 6525 N. Sheridan Road, Chicago, IL 60626. ley, 1959, p. 587). And yet, what happens at line-end pauses is still described in ways that smack of acoustics; for example, Hartman writes, "surrounded by silence, each line becomes responsible for maintaining some internal rhythmic integrity"' (p. 56).

For Hartman, then, lineation is of primary importance for the distinction of verse from prose: "The basic principle of the line emerges and takes absolute control" (p. 92). However, the problem of identifying the reader still remains. How can one "listen to the poem" unless a particular performance or set of performances is involved? Otherwise, it would appear that the readings all would have to refer back to the theorist's (in this case Hartman's) own intuitions. Then one would be left with line-end pauses and silences that are indeed not acoustical, but psychological in a very narrow sense, limited in fact to the theorist's own psyche.

The problem is hardly a new one in literary criticism. Many of the published interpretations of literary critics are considered by empirical researchers to be nothing more than preliminary intuitive hypotheses, as is clearly the case with Hartman's use of lineation (the line isolated by line-end pauses) as the basic principle of verse unitization.

Furthermore, the claim made for "slow down" and for line-end pauses may well be completely unnecessary to establish the visual importance and usefulness of lineation to the reader. In keeping with Hartman's principle that "a poem is the language of an act of attention" (p. 12), it would in fact appear sufficient for his theoretical purposes, were lineation to simply enhance and direct attention in consort with the syntactic progression of the poem.

The present study will explore the relatively greater importance of punctuation in this regard. The research of O'Connell (1982) challenged the primacy of the poetic line as determiner of temporal unitization. Poems varied in length of line, stanza format, theme, punctuation, and specific language (German or English), and readers varied from native speakers to beginners, yet pause placement was consistently predictable at punctuated line-end and midline, but not at unpunctuated positions. 
In addition, O'Connell (1984) analyzed data collected from 39 performances of authors and actors and from 240 performances of adult readers, and developed a set of principles governing poetic oral performance: (1) The poetic line is not the unit of performance. (2) Punctuation is a major contributor to unitization. (3) Line-end and punctuation combined (or stanza, where used) best predict pause placement and duration. (4) Use of some very long pauses ( $>1 \mathrm{sec}$ ) characterizes expressive readings; indiscriminate use of pauses at line-end positions characterizes nonproficient or unexpressive readings. (5) Wide variability of articulation rate and pause duration characterizes the range of expressiveness of skilled readers.

(6) There is no single best way of performing a poem.

These principles are not intended to be comprehensive, but modifiable subject to other complex sources of variability. The methodology of temporal analysis itself is in no way intended to minimize the importance of other methods (e.g., analyses of intonation contour, rhythm, or emphasis). A variety of methods eventually must be brought to bear convergently before anything approaching a comprehensive picture of oral reading can be attained. O'Connell and Kowal's (1984) findings have provided further empirical support for these principles.

Funkhouser and O'Connell $(1984,1985)$ also challenged the primacy of the poetic line as the determiner of temporal unitization. Funkhouser and O'Connell (1984) analyzed poems written and read by e. e. cummings. Cummings' oral reading style revealed patterning of articulation rate and pausing idiosyncratic to each individual poem. Each reading was more or less independent of its visible form on the printed page. Although cummings' devices of spacing and capitalization were not reliable performance cues for his own reading, he was quite conventional in using punctuation as a cue for pausing. Cummings also did not use lines consistently as breath groups, but enjambed rather frequently. Additional research by Funkhouser and O'Connell (1985) reviewed two poetry readings by William Carlos Williams: "Botticellian Trees" (BT) and "Catholic Bells" (CB). Most of the pauses of BT did mark line-ends, but even so, a good half of the lines of the poem remained unmarked by pauses. An average of one pause per line characterized CB; however, less than half the line-ends and only 4 of 12 stanzas were marked with pauses.

In April of 1984, Seamus Heaney read and commented upon a selection of his poems at Loyola University of Chicago. Nine of these were used in the present study. Texts of the poems are to be found in Poems 1965-1975 (1980), Fieldwork (1979), and Door Into the Dark (1969). In reviewing Heaney's latest volume, Station Island, TIME (Stoler, 1985) referred to "his reputation as the best poet that Ireland has produced since Yeats" (p. 91).

Use of Heaney's own readings permits the exclusion of several sources of variance. The author as reader can hardly fail to grasp the meaning of the text or fail to agree with it; he is familiar with and accustomed to the punc- tuation style; and he does not prefer other ways of expressing the same thoughts. If punctuation does indeed affect reading performance, text read by the author should be expected to optimize the effect, which would provide a far more parsimonious and objective predictor for text segmentation in reading aloud than has been proposed to date [e.g., in models requiring syntactic analysis on the part of the reader (Brown \& Miron, 1971; Butcher, 1981; Goldman-Eisler, 1972; Grosjean \& Collins, 1979)].

The general hypothesis of this study is that punctuation and pausing are closely related and that the former can be used to predict the latter. Specifically, it is hypothesized that mean pause duration will vary systematically according to punctuated $(\mathrm{P})$ and unpunctuated (U), stanza $(\mathrm{S})$, line-end $(\mathrm{L})$, and midline $(\mathrm{M})$ position categories as follows: PS > PL > PM > US > UL > UM. The same relationships are hypothesized for the proportion of respective available positions used for pausing.

\section{METHOD}

The nine poems of Heaney used in this study were: "Digging”' (D), "Blackberry Picking"' (BP), "Personal Helicon" (PH), "A Drink of Water"” (DW), “Sunlight”' (S), “Bogland" (B), "Bog Queen” (BQ), "Punishment" (P), and "Oysters"' $(\mathrm{O})$. The poems ranged in length of written text from 138-290 syllables (syl) and in duration of delivery from 49.27-110.95 sec. Notation of punctuation was straightforward, taken from the published texts. Readings were recorded and temporal measurements made by translating acoustical energy over time onto a level recording. For this purpose, a Siemens Oscillomink L and an F-J Fundamental Frequency Meter (Type FFM 6502) were used. From these data, duration of the readings in milliseconds and number and duration of pauses were determined. A cut-off point of $130 \mathrm{msec}$ defined the minimum length of pauses, as suggested by the recent research of Hieke, Kowal, and O'Connell (1983) and of O'Connell and Kowal (1984). Any silence less than $130 \mathrm{msec}$ was not considered to be a pause. "Line" was operationally defined as a horizontal array of words with punctuation as determined by the author. Articulation rate was operationally defined as $\mathrm{syl} / \mathrm{sec}$ on-time for a given poem. On-time was derived by subtracting pause time from total reading time.

\section{RESULTS}

Pauses marked 188/190 (98.95\%) of punctuated positions in the printed corpus: $52.63 \%$ at commas, $38.95 \%$ at periods. All the poems, excluding DW, had multiple stanzas. Pauses marked 43/52 (82.69\%) of these stanzas, including all punctuated (35) and 8/17 (47.06\%) unpunctuated stanzas. Pauses also marked all 78 punctuated and 65/131 (49.62\%) unpunctuated line-ends (excluding stanzas and final lines). Finally, pauses marked 75/78 (96.15\%) punctuated and 45/1,116 (4.03\%) unpunctuated midline positions. These relationships are illustrated in Figure 1 .

A $2 \times 3(\mathrm{P}, \mathrm{U} \times \mathrm{S}, \mathrm{L}, \mathrm{M})$ ANOVA of duration of pauses yielded significance for both main factors, punctuation and position, and their interaction: $F(1,300)=$ $142.98, \mathrm{p}<.0001 ; \mathrm{F}(2,300)=54.96, \mathrm{p}<.0001$; and $\mathrm{F}(2,300)=5.66, \mathrm{p}<.004$. Duration of pauses at punctuated positions was significantly longer than at unpunc- 


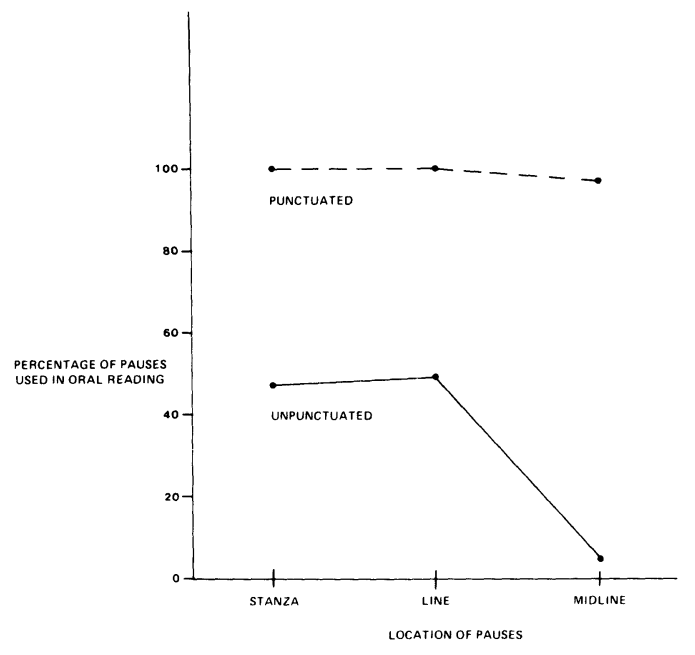

Figure 1. Percentage of pauses used in oral reading at punctuated and unpunctuated positions (stanza, line, and midline).

tuated positions ( $980>386 \mathrm{msec})$. A breakdown of the position factor yielded the following significant comparisons: $\mathrm{S}>\mathrm{L}(1,395>759 \mathrm{msec} ; \mathrm{t}(184)=6.50, \mathrm{p}<$ $.0001) ; \mathrm{S}>\mathrm{M}(1,395>510 \mathrm{msec} ; \mathrm{t}(161)=10.14$, $\mathrm{p}<.0001)$; and $\mathrm{L}>\mathrm{M}(759>510 \mathrm{msec} ; \mathrm{t}(261)=$ $4.34, \mathrm{p}<.0001)$. The interaction between the main factors reflected a greater decrement from PS through PM relative to the smaller corresponding decrement from US through UM, as illustrated in Figure 2. In the absence of punctuation, only slight differences in pause duration occurred from position to position. In summary, the hypothesized mean relationships of durations (PS $>$ PL $>$ PM > US > UL > UM) were clearly confirmed: 1,571 $>1,032>650>621>431>278 \mathrm{msec}$.

For the entire corpus, $91.97 \%$ of pause time was at punctuated positions, ranging from $83.79 \%$ (DW) to 98.68\% (BQ). The corresponding percentage of all pauses at punctuated positions was $68.95 \%$, ranging from $41.38 \%(\mathrm{~S})$ to $88.88 \%(\mathrm{PH})$. Only $5.45 \%$ of all pause time and $4.03 \%$ of the number of pauses were at unpunctuated midline positions.

Mean pauses per line ranged from $.87(\mathrm{BQ})$ to 1.87 (BP). However, BQ, which averaged nearly one pause per line, actually had 15/56 (26.79\%) line-ends without any pauses. None of these were marked by punctuation. Pauses marked $65.21 \%$ of line-ends (including stanza positions) in BP; however, these pauses accounted for only $50.07 \%$ of the pause time, and $10 / 15(66.67 \%)$ of them were marked by punctuation. In both these poems (representing the high and low extremes of pauses per line), punctuation rather than the line best predicted pause placement. One poem (P) came closest to having one pause per line (.93), with 29 line-end pauses (including stanza positions) and 21 of them (72.41\%) marked by punctuation. Heaney paused at only $8 / 22(36.36 \%)$ of those not marked by punctuation.
Articulation rate for the entire corpus was $3.96 \mathrm{syl} / \mathrm{sec}$ on-time, ranging from 3.68 (BQ) to 4.48 (DW). The average time to speak each phrase (on-time between pauses) was $1.55 \mathrm{sec}$, ranging from 1.17 (S) to 1.92 (D). The average on-time per line was $1.81 \mathrm{sec}$, ranging from 1.26 (S) to 2.57 (BP). Hence, Turner and Pöppel's (1983) assertion of the "prevalence of the 3-second LINE in human poetry" (p. 293) was disconfirmed in the present corpus with respect to both phrase and line.

\section{DISCUSSION}

The reader of this corpus of poetry did indeed use punctuation rather than the line to unitize his performance. More than $98 \%$ of the textual punctuation was used for pauses, accounting for more than $68.95 \%$ of number of pauses in the readings. As hypothesized, the use of punctuation for pausing was ordered as follows: PS $>$ PL $>$ PM $>$ US $>\mathrm{UL}>\mathrm{UM}$, for the two response measures, pause duration and (except, US $\approx \mathrm{UL}$ ) proportion of available positions used for pausing.

Hartman's (1980), Dillon's (1976), and Turner and Pöppel's (1983) arguments that the poetic line best accounts for the temporal unitization of oral poetry performance are clearly counterindicated by the present study. Lehiste's (1984) moderate view is more compatible with these findings. Punctuation accounted for $91.97 \%$ of the total pause time in this sample of poems. This is not to deny the importance of the line in poetry; $186 / 309(60.19 \%)$ of the pauses in this corpus were at lineend (including stanza) positions. It is rather to emphasize that not all lines are created equal; 73/148 (49.32\%) unpunctuated line-end (including stanza) positions were not marked with pauses.

The temporal unitization of a poem is a function of the author's use of punctuation both in and about the poetic line. There is no evidence that a reader generally needs to carry out a syntactic analysis in order to allocate pauses. Punctuation serves as a parsimonious and efficient predictor of pause duration and pause placement.

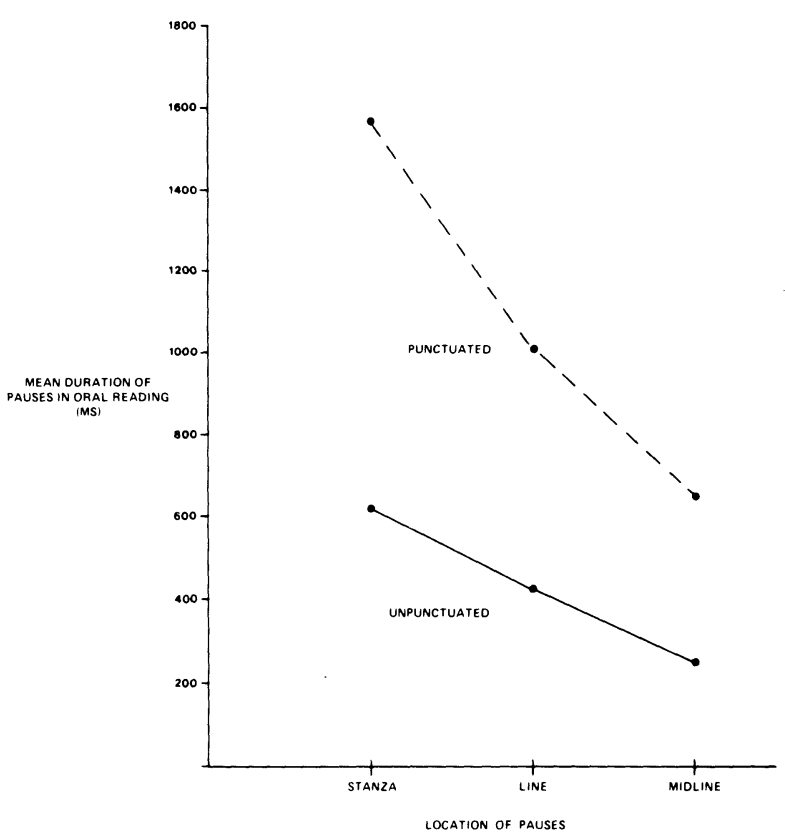

Figure 2. Mean duration of pauses (msec) in oral reading at punctuated and unpunctuated positions (stanza, line, and midline). 


\section{REFERENCES}

Brown, E., \& Miron, M. S. (1971). Lexical and syntactic predictors of the distribution of pause time in reading. Journal of Verbal Learning \& Verbal Behavior, 10, 658-667.

BuTCHER, A. (1981). Aspects of the speech pause: Phonetic correlates and communicative functions. Kiel, West Germany: Institut für Phonetik der Universität Kiel.

Dillon, G. L. (1976). Clause, pause, and punctuation in poetry. Linguistics, 169, 5-20.

FUnKHouser, L., \& O'CoNNELl, D. C. (1984). Cummings reads cummings. Language \& Literature, 9, 91-126.

Funkhouser, L., \& O'ConNell, D. C. (1985). "Measure"' in William Carlos Williams' poetry: Evidence from his readings. Journal of Modern Literature, 12, 26-42.

Goldman-Eisler, F. (1972). Pauses, clauses, sentences. Language \& Speech, 15, 103-113.

Grosjean, F., \& Collins, M. (1979). Breathing, pausing, and reading. Phonetica, 36, 98-114.

Hartman, C. O. (1980). Free verse: An essay on prosody. Princeton, NJ: Princeton University Press.

Heaney, S. (1969). Door Into the Dark. London: Faber and Faber. Heaney, S. (1979). Fieldwork. New York: Farrar, Straus, and Giroux.

Heaney, S. (1980). Poems 1965-1975. New York: Farrar, Straus, and Giroux.
Heaney, S. (1985). Station Island. New York: Farrar, Straus, and Giroux.

Hieke, A., Kowal, S., \& O'Connell, D. C. (1983). The trouble with articulatory pauses. Language \& Speech, 26, 203-213.

LEHISTE, I. (1984, June). Rhythm in spoken sentences and read poetry. Paper presented at the International Phonology Meeting, Eisenstadt, Austria.

O'CoNNELL, D. C. (1982). Performance characteristics of poetry: Some cross-linguistic comparisons. Psychological Research, 44, 381-392.

O'CONNELL, D. C. (1984, April). Will the real poem please stand up? Paper presented at the Conference on Linguistics in the Humanities and Sciences, Birmingham, AL.

O'Connell, D. C., \& Kowal, S. (1984). Comparisons of native and foreign language poetry readings: Fluency, expressiveness, and their evaluation. Psychological Research, 46, 301-313.

StOLER, P. (1985, February 25). Inspirations. TIME, pp. 91-92.

Turner, F., \& PöPPEl, E. (1983). The neural lyre: Poetic meter, the brain, and time. Poetry, 142, 273-309.

Wimsatt, W. K., \& BeardsLey, M. C. (1959). The concept of meter: An exercise in abstraction. Publication of the Modern Language Association, 74, 585-598.

(Manuscript received for publication April 4, 1985.) 